\title{
A qualitative evidence synthesis on the management of male obesity: the ROMEO Project
}

\author{
Association for the Study of Obesity (ASO) \\ UK Congress on Obesity, University of Birmingham, 16 \\ September 2014
}

Daryll Archibald ${ }^{1}$, Flora Douglas ${ }^{2}$, Pat Hoddinott ${ }^{3}$, Edwin van Teijlingen ${ }^{4}$, Alison Avenell ${ }^{5}$ Clare Robertson ${ }^{5}$ \& Fiona Stewart ${ }^{5}$

1Scottish Collaboration for Public Health Research and Policy, University of Edinburgh

${ }^{2}$ Rowett Institute of Health and Nutrition, University of Aberdeen.

${ }^{3}$ School of Nursing, Midwifery and Health, University of Stirling

${ }^{4}$ Centre for Midwifery, Maternal \& Perinatal Health, School of Health \& Social Care, University of Bournemouth

${ }^{5}$ Health Services Research Unit, University of Aberdeen

\author{
Health Services Research Unit \\ University of Aberdeen
}

HSRU is funded by the Chief Scientist Office of the Scottish Government Health Directorates. The author accepts full responsibility for this talk. 


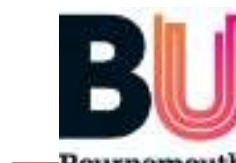

University

A collaborative project between Universities of Aberdeen, Stirling and Bournemouth, with a project advisory group from the Men's Health Forums

Project grant holders Men's Health Forums' representatives

Alison Avenell David Wilkins (E \& W)

Flora Douglas Tim Street (Scotland)

Pat Hoddinott Paula Carroll, Colin Fowler (Ireland)

Edwin van Teijlingen

\section{Researchers}

Clare Robertson, Daryll Archibald, Dwayne Boyers, Fiona Stewart, Charles Boachie, Evie Fioratou 


\section{The Problem}

- More men than women are overweight or obese in the UK

- Men:

$>$ Tend to misperceive their weight

$>$ Are less likely to consider their weight a health risk

$>$ Are less likely to attempt weight loss 


\section{Aim of the ROMEO study}

- To identify effective interventions, and how effective interventions work, by describing key intervention ingredients, processes, environmental and contextual factors that contribute to effectiveness. 


\section{What we did}

Systematic review and realist synthesis:

1. 11 RCTs of long-term lifestyle or drug (orlistat) interventions

2. 20 RCTs of long-term lifestyle or drug (orlistat) interventions for men compared to women

3. 26 reports of interventions for men, or men compared to women from the UK

4. Systematically reviewed qualitative research with men:

i. Taking part in weight loss programmes

ii. Who weren't taking part in weight loss programmes

5. Economic evaluations of interventions for men, or men compared to women 


\section{QES Methods}

- Search strategy: Eight bibliographic databases were searched to identify qualitative research with obese men, or obese men in contrast to obese women.

- Inclusion criteria: Studies published from 1990 onwards in any language. The studies included men 16 years or over, with no upper age limit, with a mean or median BMI of $30 \mathrm{~kg} / \mathrm{m}^{2}$.

- Quality assessment: A quality appraisal tool was applied during the process of data extraction but no exclusions were made on quality grounds.

- Data analysis: An analysis cycle began with data coding. Initial descriptive themes were identified. Finally, higher order interpretive themes and concepts were developed through research team discussion. 


\section{Included Studies}

Twenty-two studies were included.

- Five qualitative studies linked to RCTs of weight loss or weight maintenance interventions.

- Eight qualitative studies linked to non-RCT studies.

- Nine qualitative studies not linked to any intervention. 


\section{Logic model}

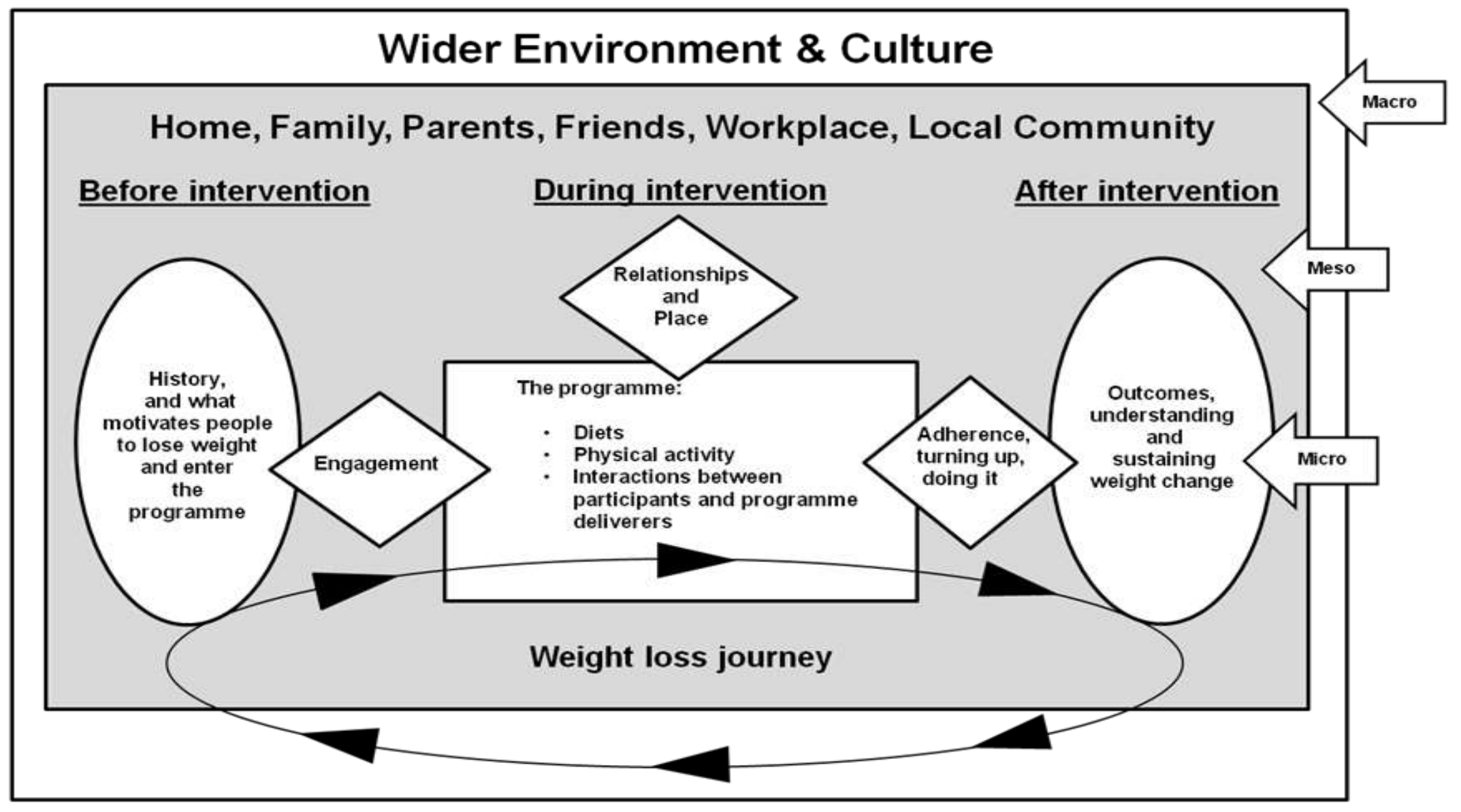




\section{Motivation for joining}

- Men were motivated to engage with weight management programmes because of:

$>$ health concerns

$>$ obesity diagnosis

$>$ 'jolts' from a partner

$>$ perceptions that certain programmes had 'worked' for other men

$>$ humour in promotional materials

$>$ settings that were convenient, non-threatening and congruent with masculine identities

$>$ potential to improve physical fitness

$>$ offers of health screening 


\section{Motivation for joining: illustrative quotes}

\section{- Health Scares:}

"Having a heart attack really scared me. I just wanted to feel better, see my kids grow up, and be more in control. I had tried so many things, but being in hospital really brought me to my senses." John, age 38 (Gallagher et al. 2012:21).

\section{- Diagnosis of Obesity:}

"It really hit me like a ton of bricks, I mean I knew I had been putting on weight over the years and thought the tests would show that I was a bit fat, but finding out I was obese really knocked me for six. "John, age 42 (Leishman 2007:49). 
What makes the programme more effective for men? (1)

- Avoiding strict or extreme diets or dieting terms

- Provision of factual information about energy balance

- Provision of individual tailoring

- Using self-monitoring and feedback

- Follow-up after end of programme

- Family and friends important influences, and they may change behaviour too 


\section{What makes the programme more effective for men? Illustrative quotes}

\section{- Avoiding strict or extreme diets or dieting terms:}

"I was pleasantly surprised to find out that this was not a diet I was on but actually a course to educate us men on eating healthier, the need to be more active and to control our portions. At first I didn't think it would work for me because I felt I was eating the same amount of food I always had, just more fruit and veg. "No individual characteristics provided (Leishman 2007:85).

- Provision of factual information about energy balance:

'Once I'd actually lost some weight by staying under my energy count and then put on some weight by going over, I went this really works, it's really clear. . . that motivated me from then on. . .Definitely the success kept me going. "Age 43 (Morgan et al. 2011b:e245). 


\section{What makes the programme more effective for men? (2)}

Groups:

- Some men wanted men-only groups

- Peer social support appreciated, even for men who did not initially want to take part in a group

- Humour and banter amongst group members 


\section{What makes the programme more effective for men? (2)}

- Men only groups:

"thought I'll go along 'cos it was all blokes anyway, 'cos I wasn't going to go, with all due respect, with the women." No individual characteristics provided (Gray et al. (2009:77).

- Humour and banter amongst group members:

"There was quite a good crack going on all the time, so the following week you kinda felt you wanted to come back and hear how the guys were getting on. "No individual characteristics provided (Gray and colleagues 2009:77). 


\section{Recommendations for practice (1)}

- Men appear to prefer more factual information on how to lose weight and more emphasis on providing physical activity programmes.

- For some men, but not all, the opportunity to attend men-only groups may enhance effectiveness. 


\section{Recommendations for practice (2)}

- Weight-loss programmes for men may be better provided in social settings, such as sports clubs and workplaces, which may be more successful at engaging men than health service settings. 


\section{Recommendations for practice (3)}

- Individual tailoring and feedback may also be features of more effective services.

- Innovative means of delivering services are needed for hard to reach groups, such as those men who do not see their weight status as a problem, younger men, unemployed men and those living in remote and rural locations. 


\section{Recommendations for practice (4)}

- Health service staff can be encouraged to recognise 'teachable moments', when a health issue could become a motivator for a man to lose weight.

- Health service staff should initiate discussion and provide opportunities to access weight loss services, particularly for men from disadvantaged groups.

- Policies and services to prevent and treat obesity should take account of sex and gender-related differences, and consult men in the development and evaluation of services. 


\section{Thanks for your attention}

Acknowledgements:

- This project was funded by the National Institute for Health Research Health Technology Assessment (NIHR HTA) programme (09/127/01) and has been published as a Health Technology Assessment monograph.

- The views and opinions expressed therein are those of the authors and do not necessarily reflect those of the HTA programme, NIHR, NHS or the Department of Health.

- Final report published May 2014

http://www.journalslibrary.nihr.ac.uk/hta/volume-18/issue-35

National Institute for

Health Research 


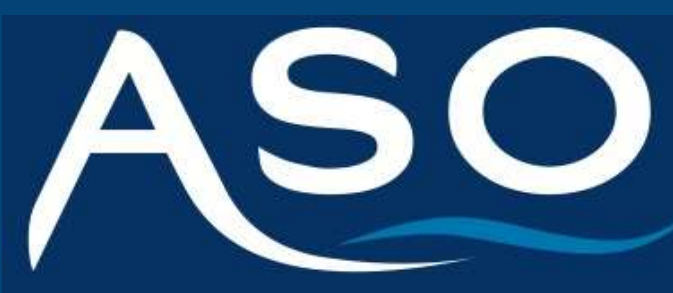

ASSOCIATION FOR THE STUDY OF OBESITY

\section{UK Congress on Obesity 2014}

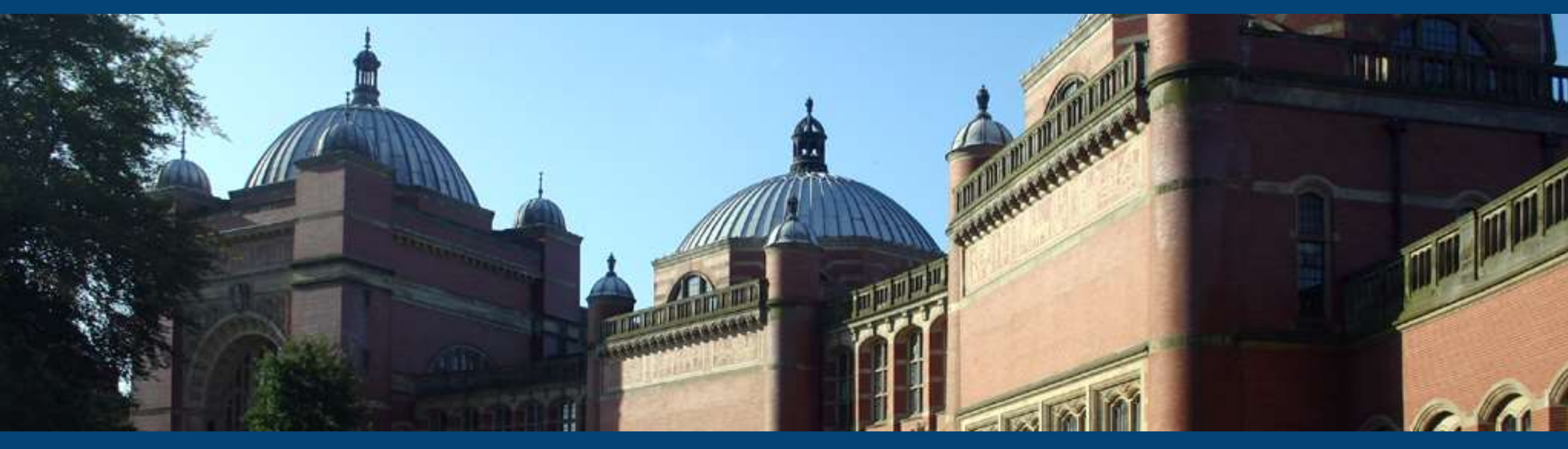

University of Birmingham, Edgbaston Campus Tuesday 16th September and Wednesday 17th September 2014 